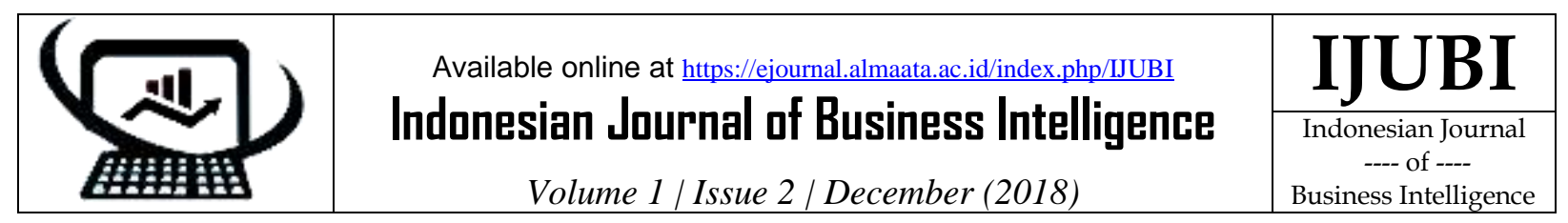

\title{
SISTEM PENDUKUNG KEPUTUSAN DENGAN MENGGUNAKAN MENGGUNAKAN METODE MULTI ATRIBUTE UTILITY THEORY (MAUT) UNTUK PENENTUAN BANTUAN RUMAH TINGGAL SEHAT
}

Wahyu Widodo', Idi Nastoto ${ }^{2}$

${ }^{12}$ Teknik Informatika, STMIK El Rahma

${ }^{1}$ wahyu@stmikelrahma.ac.id, ${ }^{2}$ nastoto@ gmail.com

${ }^{12} \mathrm{Jl}$. Sisingamangaraja No.76 Karangkajen Mergangsang Yogyakarta

\begin{abstract}
Keywords:
Decision support system, multi attribute utility theory, home stay healthy.
\end{abstract}

Kata Kunci:
Sistem pendukung
keputusan, multi
attribute utility
theory, rumah
tinggal sehat.

Kata Kunci:

Sistem pendukung

keputusan, multi

attribute utility

tinggal sehat.

\begin{abstract}
Candi is one of the villages in Gunungkidul Regency, Special Region of Yogyakarta. Candi Village has 20 hamlets. In the area of the Candi Village, there are houses which are healthy and houses are not healthy. With the area of 20 hamlets, the village of Candi has difficulty in determining a healthy home to live and an unhealthy house to live. From the above problems, the decision support system is a necessity to resolve the Government problems in Candirejo Village. Decision support systems are designed using the Multi Attribute Utility Theory (MAUT) method. To determine which houses stay healthy or not healthy, there are 23 criteria, with two alternatives. With the establishment of a decision support system using the MAUT method, the Government of Candirejo Village can easily determine which houses are healthy living and unhealthy homes.
\end{abstract}

Abstrak
Candi merupakan salah satu desa yang berada di Kabupaten Gunungkidul,
Daerah Istimewa Yogyakarta. Desa Candi memiliki 20 dusun. Di wilayah Desa
Candi tesebar rumah - rumah penduduk terdapat rumah tinggal sehat dan
rumah tinggal tidak sehat. Dengan wilayah 20 Dusun Pemerintah Desa Candi
kesulitan dalam menentukan rumah sehat tinggal dan rumah tidak sehat
tinggal. Dari permasalahan di atas maka sistem pendukung keputusan
menjadi suatu kebutuhan untuk menyelesaikan permasalahan Pemerintah
Desa Candirejo. Sistem pendukung keputusan dirancang dengan
mengunakan metode Multi Attribute Utility Theory (MAUT). Untuk
menentukan rumah tinggal sehat atau tidak sehat, terdapat 23 kriteria, dengan
dua alternative. Dengan dibuatnya sistem pendukung keputusan
menggunakan metode MAUT Pemerintah Desa Candirejo bisa dengan mudah
menentukan rumah sehat tinggal dan rumah tidak sehat tinggal.

\section{Pendahuluan}

Candi merupakan salah satu desa yang berada di Kabupaten Gunungkidul, Daerah Istimewa Yogyakarta yang memiliki 20 Dusun dan tidak semua penduduk memiliki rumah sehat. Saat ini Pemerintah Desa Candi sedang melakukan seleksi penentuan bantuan bagi penduduk yang memiliki rumah tidak sehat. Proses seleksi dilakukan secara manual sehingga kesulitan dalam menentukan rumah tinggal penduduk masuk kategori rumah sehat atau rumah tidak sehat. Terkadang proses seleksi manual mengakibatkan kesenjangan social dan sebagian mengklaim pemerintah desa tidak adil dalam memutuskan pemberian bantuan. Hal tersebut dikarenakan sistem pengambilan keputusan masih dilakukan dengan cara yang manual.

Dari uraian di atas maka sistem pendukung keputusan menjadi suatu kebutuhan untuk menyelesaikan permasalahan Pemerintah Desa Candi. Sistem pendukung keputusan yang dibuat menggunakan metode Multi Attribute Utility Theory (MAUT). Multi Attribute Utility Theory merupakan metode sistem pendukung keputusan 
yang digunakan untuk merubah dari beberapa kepentingan kedalam nilai numerik dengan skala 0-1 dengan 0 mewakili pilihan terburuk dan 1 terbaik [1][4][5]. Dari hal tersebut maka sistem pendukung keputusan dengan metode MAUT tepat digunakan untuk menentukan rumah tinggal sehat, dimana data yang digunakan, dari beberapa kepentingan harus dirubah ke nilai numerik.

\section{Landasan Teori}

Sistem pendukung keputusan atau Decision Support Sistem (DSS) merupakan sistem informasi interaktif yang menyediakan informasi, pemodelan, dan pemanipulasian data. Sistem itu digunakan untuk membantu pengambilan keputusan dalam situasi yang semterstruktur dan situasi yang tidak terstruktur, dimana tidak seorang pun tahu secara pasti bagaimana keputusan dibuat [2].

Dalam Undang-undang Nomor 4 Tahun 1992 tentang Perumahan dan Permukiman, perumahan adalah kelompok rumah yang berfungsi sebagai lingkungan tempat tinggal atau lingkungan hunian yang dilengkapi dengan prasarana dan sarana lingkungan. Rumah yang di maksud dalam alinea pertama adalah bangunan yang berfungsi sebagai tempat tinggal atau hunian dan sarana pembinaan keluarga[3]. Menurut $\mathrm{WHO}$, rumah adalah struktur fisik atau bangunan untuk tempat berlindung, dimana lingkungan berguna untuk kesehatan jasmani dan rohani serta keadaan sosialnya baik untuk kesehatan keluarga dan individu.

Dengan demikian dapat dikatakan bahwa rumah sehat adalah bangunan tempat berlindung dan beristirahat serta sebagai sarana pembinaan keluarga yang menumbuhkan kehidupan sehat secara fisik, mental dan sosial, sehingga seluruh anggota keluarga dapat bekerja secara produktif. Oleh karena itu keberadaan perumahan yang sehat, aman,serasi, teratur sangat diperlukan agar fungsi dan kegunaan rumah dapat terpenuhi dengan baik.

Ada 23 kriteria $(\mathrm{K} n)$ untuk menentukan rumah sehat. Berikut kriteria rumah sehat menurut KEMENKES 829 TAHUN 1999 seperti berikut.
K1 : Terbuat dari bahan yang dapat melepas zat-zat yang dapat membahayakan kesehatan, antara lain, debu total tidak lebih dari $150 \mu \mathrm{g} / \mathrm{m} 3$, asbes bebas tidak melebihi 0,5 fiber $/ \mathrm{m} 3 / 4$ jam dan Timah hitam tidak melebihi $300 \mathrm{mg} / \mathrm{kg}$.

K2 : Terbuat dari bahan yang dapat memicu tumbuh dan berkembangnya mikroorganisme patogen.

K3 : Lantai yang kedap air dan mudah dibersihkan.

K4 : Dinding, Di ruang tidur dan ruang keluarga dilengkapi dengan ventilasi untuk pengaturan sirkulasi udara. Kamar mandi dan tempat cuci harus kedap air dan mudah dibersihkan.

K5 : Langit-langit harus mudah dibersihkan dan tidak rawan kecelakaan.

K6 : Bubungan rumah yang memiliki tinggi lebih dari sama dengan $10 \mathrm{~m}$ harus dilengkapi dengan penangkal petir.

K7 : Ruang di dalam rumah harus ada ruang tamu, ruang keluarga, ruang makan, ruang tidur, ruang dapur, ruang mandi, dan ruang bermain anak.

K8 : Ruang dapur harus memiliki pembuangan asap.

K9 : Pencahayaan dalam ruangan harus dapat menerangi seluruh ruangan. Intensitas minimal pencahayaan dalam ruangan adalah 60 lux dan tidak menyilaukan.

K10 : Suhu udara berkisar $18^{\circ}$ sampai $30^{\circ} \mathrm{C}$.

K11: Kelembapan udara berkisar antara $40 \%$ sampai $70 \%$.

K12: Konsentrasi gas SO2 tidak melebihi 0,10 ppm/24 jam.

K13 : Pertukaran udara (air exchange rate) = 5 kaki kubik per menit per penghuni.

K14 : $\quad$ Konsentrasi gas CO tidak melebihi 100 ppm/8 jam.

K15: Konsentrasi gas formaldehid tidak melebihi $120 \mathrm{mg} / \mathrm{m} 3$.

K16 : Luas ventilasi alamiah yang permanen minimal $10 \%$ dari luas lantai.

K17 : Tikus bersarang di dalam runah.

K18 : Tersedia air bersih minimal 60 liter/hari/orang. 
K19: Kualitas air harus memenuhi persyaratan kesehatan air bersih dan air minum sesuai perundangundangan yang berlaku.

K20 : Memiliki sarana penyimpanan makanan yang aman.

K21 : Limbah cair mencemari sumber air, menimbulkan bau, dan mencemari permukaan tanah.

K22: Limbah padat menimbulkan bau, pencemaran terhadap permukaan tanah, serta air tanah.

K23: Luas ruang tidur minimal 9 meter,tidak digunakan lebih dari du orang, kecuali anak di bawah umur 5 tahun.

Sistem pendukung keputusan ini menggunakan 2 alternatif yaitu sehat (A1) dan tidak sehat (A2).

\section{Metode}

Multi Attribute Utility Theory (MAUT) digunakan untuk merubah dari beberapa kepentingan kedalam nilai numerik dengan skala $0-1$ dengan 0 mewakili pilihan terburuk dan 1 terbaik. Hal ini memungkinkan perbandingan langsung yang beragam ukuran [1]. Hasil akhirnya adalah urutan peringkat dari evaluasi alternatif yang menggambarkan pilihan dari para pembuat keputusan. Nilai evaluasi seluruhnya dapat didefinisikan dengan persamaan 1 .

$$
v(x)=\sum_{i=1}^{n} w i v i(x)
$$

Dimana $\mathrm{v}(\mathrm{x})$ merupakan nilai evaluasi dari sebuah objek ke i dan wi merupakan bobot yang menentukan nilai dari seberapa penting elemen ke $\mathrm{i}$ terhadap elemen lainnya. Sedangkan $\mathrm{n}$ merupakan jumlah elemen. Total dari bobot adalah 1 , seperti pada persamaan 2 .

$$
\sum_{1=1}^{n} w i=1
$$

Untuk setiap dimensi, nilai evaluation vi(x) didefinisikan sebagai penjumlahan dari atributatribut yang relevan, seperti pada persamaan 3 .

$$
\operatorname{vi}(x)=\sum_{a \in A} w a i . v a i(I(a))
$$

Secara ringkas [7-9], langkah-langkah dalam metode MAUT adalah sebagai berikut.

1. Pecah sebuah keputusan ke dalam dimensi yang berbeda.

2. Tentukan bobot relatif pada masing-masing dimensi.

3. Daftar semua alternatif.

4. Masukkan utility untuk masing-masing alternative sesuai atributnya.

5. Kalikan utility dengan bobot untuk menemukan nilai masing-masing alternatif.

Dalam metode ini digunakan juga normalisasi matriks seperti pada persamaan 4 .

$$
U(x)=\frac{x-x_{i}^{-}}{x_{i}^{+}-x_{i}^{-}}
$$

Keterangan.

$\mathrm{U}(\mathrm{x})=$ Normalisasi bobot alternative

$X=$ Bobot alternative

$x_{i}^{-}=$Bobot alternative terburuk (minimum)

$x_{i}^{+}=$Bobot alternative terburuk (maksimum)

\section{Hasil dan Pembahasan}

Pada sistem pendukung keputusan ini menggunakan bobot kriteria yang dinyatakan dalam bilangan 0-1. Bobot sub kriteria dinyatakan dalam bilangan 0-1, sub kriteria YA digunakan untuk mengisi bobot SEHAT dan TIDAK SEHAT, seta sub kriteria TIDAK juga untuk mengisi bobot SEHAT dan TIDAK SEHAT. Dari data diata dapat diambil contoh dengan dari satu rumah. Hasil data yang diperoleh dari satu rumah dapat dilihat dalam tabel 1 berikut ini.

Tabel 1. Hasil Data yang Diperoleh

\begin{tabular}{ccccc}
$\begin{array}{c}\text { Kode } \\
\text { Kriteria }\end{array}$ & $\begin{array}{c}\text { Bobot } \\
\text { Kriteria }\end{array}$ & Sub Kriteria & \multicolumn{2}{c}{$\begin{array}{c}\text { Hasil Bobot } \\
\text { Alternatif }\end{array}$} \\
\cline { 3 - 5 } & & Tidak & 0,79 & 0,21 \\
K1 & 0,07 & Ya & 0,29 & 0,71 \\
K2 & 0,04 & Ya & 0,78 & 0,22 \\
K3 & 0,04 & Ya & 0,80 & 0,20 \\
K4 & 0,06 & Tidak & 0,28 & 0,72 \\
K5 & 0,03 & & &
\end{tabular}

IJUBI - VOL. 1 No. 2 (2018): 76 - 80 


\begin{tabular}{ccccc}
\hline $\begin{array}{c}\text { Kode } \\
\text { Kriteria }\end{array}$ & $\begin{array}{c}\text { Bobot } \\
\text { Kriteria }\end{array}$ & Sub Kriteria & \multicolumn{2}{c}{$\begin{array}{c}\text { Hasil Bobot } \\
\text { Alternatif }\end{array}$} \\
\cline { 4 - 5 } K6 & & & A1 & A2 \\
K7 & 0,03 & Tidak & 0,30 & 0,70 \\
K8 & 0,04 & Ya & 0,70 & 0,30 \\
K9 & 0,07 & Ya & 0,79 & 0,21 \\
K10 & 0,04 & Tidak & 0,24 & 0,76 \\
K11 & 0,03 & Ya & 0,77 & 0,23 \\
K12 & 0,04 & Ya & 0,70 & 0,30 \\
K13 & 0,04 & Tidak & 0,33 & 0,67 \\
K14 & 0,04 & Tidak & 0,30 & 0,70 \\
K15 & 0,05 & Tidak & 0,28 & 0,72 \\
K16 & 0,03 & Ya & 0,70 & 0,30 \\
K17 & 0,04 & Ya & 0,77 & 0,23 \\
K18 & 0,03 & Ya & 0,25 & 0,75 \\
K19 & 0,07 & Tidak & 0,28 & 0,72 \\
K20 & 0,05 & Tidak & 0,29 & 0,71 \\
K21 & 0,04 & Ya & 0,70 & 0,30 \\
K22 & 0,04 & Tidak & 0,72 & 0,28 \\
K23 & 0,04 & Ya & 0,30 & 0,70 \\
\hline
\end{tabular}

Dari data yang di peroleh diatas maka dapat di ambil nilai minimum dan maksimum dari setiap alternatif. Nilai minimum dan maksimum dapat di lihat pada tabel 2 berikut ini.

Tabel 2. Nilai Maksimum dan Minimum Alternatif

\begin{tabular}{clc}
\hline Alternatif & \multicolumn{1}{c}{ Keterangan } & Nilai \\
\hline A1 & Nilai Maksimum & 0,80 \\
A1 & Nilai Minimum & 0,24 \\
A2 & Nilai Maksimum & 0,76 \\
A2 & Nilai Minimum & 0,20 \\
\hline
\end{tabular}

Langkah selanjutnya mencari nilai utility pada setiap criteria dan alternative dengan menggunakan rumus persamaan 4 . Contoh perhitungannya seperti pada tabel 3 berikut ini.

Tabel 3. Normalisasi Bobot Alternatif

\begin{tabular}{lll}
\hline Normalisasi & \multicolumn{2}{c}{ Hasil } \\
\cline { 2 - 3 } bobot alternative & A1 & \multicolumn{1}{c}{ A2 } \\
UK1 & 0,982142857 & 0,017857143 \\
UK2 & 0,089285714 & 0,910714286 \\
UK3 & 0,089285714 & 0,910714286 \\
UK4 & 1 & 0 \\
UK5 & 0,071428571 & 0,928571429 \\
UK6 & 0,107142857 & 0,892857143 \\
UK7 & 0,821428571 & 0,178571429 \\
UK8 & 0,982142857 & 0,017857143 \\
UK9 & 0 & 1 \\
UK10 & 0,946428571 & 0,053571429 \\
UK11 & 0,821428571 & 0,178571429 \\
UK12 & 0,160714286 & 0,839285714 \\
UK13 & 0,107142857 & 0,892857143 \\
UK14 & 0,071428571 & 0,928571429 \\
UK15 & 0,821428571 & 0,178571429 \\
UK16 & 0,946428571 & 0,053571429
\end{tabular}

\begin{tabular}{lcc}
\hline Normalisasi & \multicolumn{2}{c}{ Hasil } \\
\cline { 2 - 3 } bobot alternative & A1 & A2 \\
UK17 & 0,017857143 & 0,982142857 \\
UK18 & 0,071428571 & 0,928571429 \\
UK19 & 0,089285714 & 0,910714286 \\
UK20 & 0,821428571 & 0,178571429 \\
UK21 & 0,857142857 & 0,053571429 \\
UK22 & 0,107142857 & 0,892857143 \\
UK23 & 0,910714286 & 0,089285714 \\
\hline
\end{tabular}

Setelah diperoleh nilai normalisasi bobot alternative, kemudian mengalikan hasil nilai utility masing-masing alternatif di setiap kriteria dengan bobot setiap kriteria dengan menggunakan rumus persamaan (1). Contoh perhitungannya seperti pada tabel 4 berikut ini.

Tabel 4. Hasil Perhitungan

\begin{tabular}{lll}
\hline \multicolumn{1}{c}{$\begin{array}{c}\text { Nilai evaluasi } \\
\text { kriteria }\end{array}$} & \multicolumn{1}{c}{ A1 } & \multicolumn{1}{c}{ Hasil } \\
\cline { 2 - 3 } VK1 & 0,06875 & 0,00125 \\
VK2 & 0,003571429 & 0,036428571 \\
VK3 & 0,038571429 & 0,001428571 \\
VK4 & 0,06 & 0 \\
VK5 & 0,002142857 & 0,027857143 \\
VK6 & 0,003214286 & 0,026785714 \\
VK7 & 0,032857143 & 0,007142857 \\
VK8 & 0,06875 & 0,00125 \\
VK9 & 0 & 0,04 \\
VK10 & 0,028392857 & 0,001607143 \\
VK11 & 0,032857143 & 0,007142857 \\
VK12 & 0,006428571 & 0,033571429 \\
VK13 & 0,004285714 & 0,035714286 \\
VK14 & 0,003571429 & 0,046428571 \\
VK15 & 0,024642857 & 0,005357143 \\
VK16 & 0,037857143 & 0,002142857 \\
VK17 & 0,000535714 & 0,029464286 \\
VK18 & 0,005 & 0,065 \\
VK19 & 0,004464286 & 0,045535714 \\
VK20 & 0,032857143 & 0,007142857 \\
VK21 & 0,034285714 & 0,002142857 \\
VK22 & 0,004285714 & 0,035714286 \\
VK23 & 0,036428571 & 0,003571429 \\
Jum1ah & $\mathbf{0 , 5 3 3 7 5}$ & $\mathbf{0 , 4 6 6 2 5}$ \\
\hline
\end{tabular}

Untuk mendapat keputusan akhir maka bandingkan kedua nilai penjumlahan masing masing alternatif. Dari hasil perbandingan pada tabel 4.9 dapat diputuskan bawah A1 $(0,53375)$ lebih besar dari A2 $(0,46625)$ maka data rumah tersebut termasuk dalam kategori rumah tinggal sehat.

\section{Kesimpulan dan Saran}

Sistem pendukung keputusan kesehatan rumah sehat dirancang dalam bentuk website dengan mengimplementasikan metode MAUT yang 
digunakan untuk perhitungan pengambilan keputusan, dengan hasil perhitungan yang diperoleh dapat membantu pemerintah Desa dalam memutuskan pemberian bantuan untuk rumah tidak sehat. Implementasi metode MAUT dalam penelitian ini menghasilkan nilai sehat 0,53375 dan nilai tidak sehat 0,462678571 . Maka dapat disimpulkan nilai sehat mendekati nilai 1 dan nilai tidak sehat mendekati nilai 0 . Nilai yang dihasilkan tergantung pada pemberian bobot kriteria dan bobot masing-masing alternatif.

\section{Referensi}

[1] Gusdha M, E. A., Wahyudin, A., \& Nugroho, E. P. (2010). Sistem Promosi Jabatan Karyawan dengan Metode Analytical Hierarchy Process ( AHP ) dan MultiAttribute Utility Theory ( MAUT ) ( Studi Kasus pada PT . Ginsa Inti Pratama ) Prosedur Iterasi Metode AHP dan MAUT. 2010.
[2] Kusrini. (2007). Konsep Dan Aplikasi Sistem Pendukung Keputusan. Yogyakarta.

[3] Chamid, A. A. (2016). Penerapan Metode Topsis Untuk Menentukan Prioritas Kondisi Rumah. Universitas Muria Kudus, 7(2), 537544.

[4] Jannah, R. (2015). Aplikasi Penerimaan Karyawan dengan Metode Multi Attribute Utility Theory. Teknik Informatika, STMIK Amik Riau, 1(2), 79-89.

[5] Siswo, R. A., \& Rosyidah, U. A. (2017). Sistem Pendukung Keputusan Untuk Penerimaan Karyawan Pt Pln Jember Menggunakan Metode Multi Attribute Utility Theory (Maut). Universitas Muhammadiyah Jember, (1210652011). 